Int. J. Electrochem. Sci., 14 (2019) 10710 - 10719

International Journal of

ELECTROCHEMICAL

SCIENCE

WWW.electrochemsci.org

\title{
Facile synthesis of Co-Ni-Mn oxide for high performance supercapacitor
}

\author{
Qingli Sui, Cuili Xiang,", Yongjin Zou, Erhu Yan, Huangzhi Zhang, Fen Xu, Lixian Sun * \\ Guangxi Key Laboratory of Information Materials, Guilin University of Electronic Technology, Guilin \\ 541004, P.R. China \\ *E-mail: xiangcuili@guet.edu.cn; sunlx@guet.edu.cn
}

doi: $10.20964 / 2019.12 .22$

Received: 5 July 2019 / Accepted: 4 September 2019 / Published: 29 October 2019

Transition metal oxides possess unique properties for energy storage devices. In this study, Co-Ni-Mn ternary metal oxide (Co-Ni-Mn-O) was synthesized in a facile way. Co-Ni alloy was first prepared by chemical reduction and then oxidized by potassium permanganate. $\mathrm{MnO}_{2}$ was thus covered on the Co$\mathrm{Ni}$ oxides. The Co-Ni-Mn-O has high electrochemical activity and can be used for supercapacitor electrode. The Co-Ni-Mn-O demonstrates high specific capacitance as well as excellent rate capability and stability, which is promising for energy storage applications.

Keywords: $\mathrm{MnO}_{2}$; Supercapacitor; Transition mental oxides; Ternary metal oxide; Nanocomposite

\section{$\underline{\text { FULL TEXT }}$}

(C) 2019 The Authors. Published by ESG (www.electrochemsci.org). This article is an open access article distributed under the terms and conditions of the Creative Commons Attribution license (http://creativecommons.org/licenses/by/4.0/). 